\title{
Formation mechanism and improved properties of Cu95Fe5 homogeneous immiscible composite coating by the combination of mechanical alloying and laser cladding
}

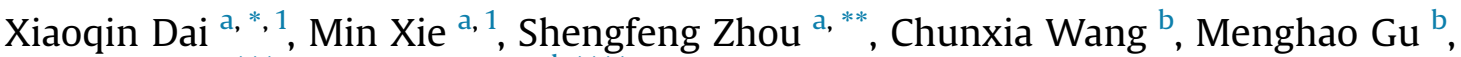 \\ Jiaoxi Yang ${ }^{\mathrm{c}, * * *}$, Zhengyang $\mathrm{Li}^{\mathrm{d}, * * * *}$ \\ a Laser Technology Institute, Tianjin Polytechnic University, Tianjin, 300387, PR China \\ b School of Materials Science and Engineering, Nanchang Hangkong University, Nanchang, Jiangxi 330063, PR China \\ c Institute of Laser Engineering, Beijing University of Technology, Beijing, 100124, PR China \\ ${ }^{\mathrm{d}}$ Institute of Mechanics, Chinese Academy of Sciences, Beijing, 10090, PR China
}

\section{A R T I C L E I N F O}

\section{Article history:}

Received 19 November 2017

Received in revised form

30 December 2017

Accepted 2 January 2018

Available online 3 January 2018

\section{Keywords:}

Immiscible alloy

Liquid phase separation

$\mathrm{Cu}-\mathrm{Fe}$

Microstructure

Magnetic properties

\begin{abstract}
A B S T R A C T
In order to improve the homogeneity of spherical Fe-rich particles within the Cu-rich matrix, the Cu95Fe5 (wt\%) immiscible composite coating has been produced by the combination of mechanical alloying and laser cladding. The results show that the milled composite powder presents a polygonal morphology and is mainly composed of face-centered-cubic (fcc)-Cu solid solution. The demixing or delimitation is eliminated in the immiscible composite coating produced by laser cladding and large amounts of spherical $\alpha$-Fe particles are dispersed within the $\varepsilon-\mathrm{Cu}$ matrix as a result of liquid phase separation (LPS). The size of the Fe-rich particles measured is in radius of $\sim 1.5 \mu \mathrm{m}$, which is much smaller than the calculated critical radius $(\sim 2.3 \mu \mathrm{m})$, confirming that the $\alpha$-Fe particles containing a supersaturated $\mathrm{Cu}$ are driven by the dominant mechanism of Marangoni motion. Compared to Brass, the immiscible composite coating exhibits the improved homogeneous microhardness $\left(153 \mathrm{HV}_{0.2}\right)$ and higher corrosion resistance, as well as a saturated magnetization of $\sim 9.19 \mathrm{emu} / \mathrm{g}$ and low coercivity of $\sim 9.25$ Oe. (c) 2018 Elsevier B.V. All rights reserved.
\end{abstract}

\section{Introduction}

The remarkable characteristic of immiscible alloys is that there is a metastable liquid immiscible gap in the phase diagram. When they are supercooled below a certain temperature of liquid miscibility gap $\left(\mathrm{T}_{\mathrm{sep}}\right)$, the melt can separate into two melts as a result of liquid phase separation (LPS): a Fe-rich melt (L1) and a Cu-rich melt (L2) [1]. Especially, when the spherical particles as the minor phase are dispersed homogeneously in the metal matrix as the major phase, the immiscible alloys exhibit many unique properties. It is expected that the immiscible alloys as self-assembled composites can oppose a rich variety of potential applications, such as

\footnotetext{
* Corresponding author.

** Corresponding author.

*** Corresponding author.

$* * * *$ Corresponding author

E-mail addresses: daixq0827@163.com (X. Dai), yangjiaoxi@bjut.edu.cn (J. Yang), zyli@imech.ac.cn (Z. Li).

1 These authors contributed equally to this paper.
}

electronic packaging solders and magnetoresistive materials in the electronic industry, advanced bearings in the automotive industry, and metallic phase change materials (PCM) in latent heat storage systems [2-5].

Compared to other immiscible alloys such as $\mathrm{Cu}-\mathrm{Co}, \mathrm{Al}-\mathrm{Bi}, \mathrm{Cu}-$ $\mathrm{Ag}, \mathrm{Fe}-\mathrm{Sn}-\mathrm{Ge}, \mathrm{Al}-\mathrm{Co}-\mathrm{La}-\mathrm{Pb}$ and etc [6-10], the $\mathrm{Cu}-\mathrm{Fe}$ immiscible alloys have attracted extensive attention. This is attributed to the fact that copper has good corrosion resistance, high thermal and electrical conductivity, and iron has good hardness, wear resistance and low cost [11-13]. Moreover, most researchers focused on the solidification dynamics and mechanisms of LPS in the $\mathrm{Cu}-\mathrm{Fe}$ immiscible alloys. However, the LPS is susceptible to result in serious macrostructure segregation within the $\mathrm{Cu}-\mathrm{Fe}$ immiscible alloys [14-16]. In order to overcome this disadvantage, extensive efforts have been made in an attempt to obtain bulk homogeneous $\mathrm{Cu}-\mathrm{Fe}$ immiscible alloys [17-19], such as electromagnetic levitation [20], combustion synthesis [17], drop tube [21] and gas atomization [22]. However, the rapid growth and coalescence of the minority phase droplets (MPDs) are essentially unavoidable due to Marangoni motion, even under the microgravity required to overcome 
the effect of gravity on the microstructure segregation [7].

Generally, mechanical alloying (MA) is considered to an advanced technique to induce solid-state reactions. It has been shown to be capable of producing a variety of nanostructures, metastable crystalline and quasicrystalline phases, amorphous alloys and immiscible alloys [23-27]. Moreover, laser cladding has a cooling rate as high as $10^{5} \sim 10^{7} \mathrm{~K} / \mathrm{s}$, which, in turn, can lead to microstructure refinement, enhanced solid solubility and considerable dynamic supercooling [28]. Therefore, it has great potential in processing immiscible alloys compared to traditional solidification methods (e.g. casting). The previous results showed that the phase separation characteristics and properties of the $\mathrm{Cu}-\mathrm{Fe}$ immiscible composite coatings depend not only on the inoculant addition of CNTs [12], alloying element addition of Al [29], but also on substrate type [15] and laser scanning speed [30]. However, the demixing and delamination still occur in the $\mathrm{Cu}-\mathrm{Fe}$ immiscible composite coatings by LIHC. In order to eliminate the phenomenon of demixing and delamination in the $\mathrm{Cu}-\mathrm{Fe}$ immiscible composite coatings, the chemical composition is designed according to the $\mathrm{Cu}-$ Fe phase diagram [31] and the Cu95Fe5 (wt\%) homogeneous immiscible composite coating without demixing and delamination was successfully prepared by the combination of mechanical alloying and laser cladding in the present paper. The emphasis is to investigate the formation mechanisms and improved properties (microhardness, electrochemical resistance and soft magnetic properties) of the immiscible composite coating.

\section{Experimental procedures}

\subsection{Laser cladding}

The carbon steel was used as substrate with dimensions of $100 \mathrm{~mm} \times 50 \mathrm{~mm} \times 10 \mathrm{~mm}$. The composite powder was composed of $95 \mathrm{wt} \%$ pure copper (99.5\%) and $5 \mathrm{wt} \% \mathrm{Fe}-12 \mathrm{Ni}-5 \mathrm{Cr}-0.6 \mathrm{Si}-0.2 \mathrm{C}$ powder, which was marked $\mathrm{Cu} 95 \mathrm{Fe} 5$. The composite powder was milled mechanically at a rate of $200 \mathrm{rpm}$ in a planetary ball mill for $8 \mathrm{~h}$. After each $30 \mathrm{~min}$ of milling, the operation was stopped for $15 \mathrm{~min}$ to avoid rising temperature. Stainless steel balls $(5 \mathrm{~mm}$ in diameter) and milling vessels were used during mechanical alloying. The powder to ball mass ratio was set to $1: 15$. After mechanical alloying, the composite powder was dried at $120{ }^{\circ} \mathrm{C}$ for $3 \mathrm{~h}$ in an electric furnace. The milled composite powder was used as cladding material.

Laser cladding was carried out with two-step method. Initially, the cladding material with a thickness of $\sim 2.0 \mathrm{~mm}$ was preplaced on the surface of the substrate, and then was melted using a semiconductor laser with a wavelength of $800 \mathrm{~nm}$ to form the Cu95Fe5 immiscible composite coating. To avoid the oxidation of the immiscible composite coating, pure Ar shielding gas was blown into the laser-induced molten pool. The processing parameters were adopted: spot size $8 \mathrm{~mm} \times 4 \mathrm{~mm}$, laser power $3 \mathrm{~kW}$, and laser scanning speed $8 \mathrm{~mm} / \mathrm{s}$.

\subsection{Microstructure characterization}

The specimens after laser cladding were cut, ground, and polished for metallographic examinations, and subsequently etched by a solution of $5 \mathrm{~g} \mathrm{FeCl}_{3}$ (99.9\%), $5 \mathrm{~mL} \mathrm{HCl}$ (37 wt\%, Analytical reagent) and $95 \mathrm{~mL} \mathrm{H}_{2} \mathrm{O}$ for $10 \mathrm{~s}$ at room temperature. The microstructure characteristic of the immiscible composite coating was observed by an optical microscope (OLYMPUS PME-3) and a scanning electron microscope (PHILIP-XL30) equipped with an energy-dispersive spectroscopy (EDS). The phase constituents of the milled composite powder and immiscible composite coating were analyzed by an X-ray diffractometer (XRD, D8 ADVANCE with Cu Ka radiation) operating at $40 \mathrm{kV}$ and $40 \mathrm{~mA}$.

\subsection{Properties characterization}

The microhardness of the immiscible composite coating was tested by an HV-1000 tester with a load of $1.96 \mathrm{~N}$ and a dwelling time of $10 \mathrm{~s}$. Electrochemical measurements (CHI 660C, Shanghai, China) were performed on a standard three-electrode cell, consisting of a working electrode (WE) made from a coating specimen with an exposed area of $1 \mathrm{~cm}^{2}$, a platinum counter electrode (CE), and a saturated calomel reference electrode (SCE). The electrolyte used was $3.5 \mathrm{wt} \% \mathrm{NaCl}$ solution. Potentiodynamic polarization curves were recorded at a sweep rate of $20 \mathrm{mV} \mathrm{min}^{-1}$, starting from the moment when the open circuit potential (OCP) reached its steady state after immersing the specimen into the electrolyte for about $1 \mathrm{~h}$. Electrochemical impedance spectroscopy (EIS) measurements were performed at the OCP potentiostatically by scanning a frequency range from $10^{-2} \sim 10^{5} \mathrm{~Hz}$ with voltage perturbation amplitude of $10 \mathrm{mV}$. The corresponding Nyquist and Bode plots were fitted by impedance spectrum data using Zsimpwin software. All potentials mentioned in this work were measured with respect to saturated calomel electrode (SCE). The magnetic properties were examined repeatedly using an MPMS-XL vibrating sample magnetometer with a maximum applied of 20,000 Oe at room temperature.

\section{Results}

\subsection{Microstructure of immiscible composite coating}

Fig. 1a shows the SEM image of the Cu95Fe5 composite powder for $8 \mathrm{~h}$ milling. The irregular powder particles indicate that copper powder and Fe-based powder suffer from a seriously repeated deformation, fracturing and cold welding [32]. With continuous milling, plastic deformation and internal stress increase, and correspondingly the internal defects such as dislocation, twin crystals and vacancies increase [32], leading to a further refinement and polygonal morphology of Cu95Fe5 composite powder. Fig. 1b shows the particle size distribution of un-milled and milled composite powder. The original powder sizes D3 and D98 are $\sim 13.82 \mu \mathrm{m}$ and $111.15 \mu \mathrm{m}$, respectively. The milled powder sizes D3 and D98 are decreased to $\sim 5 \mu \mathrm{m}$ and $80 \mu \mathrm{m}$, respectively. Obviously, the milled powder presents better concentration distribution than the un-milled powder, implying that apparent fracturing is induced after mechanical milling. Fig. 1c and d present the XRD patterns of the primary Fe-based powder and the milled composite powder. Obviously, the milled composite powder is mainly composed of face-centered-cubic (fcc)-Cu phase, whereas the body-centeredcubic (bcc) $\alpha$-Fe peaks disappear, which can be explained by the following reasons. Generally, the difference atomic radius is just $1.5 \%$ and the electro-negativities are close together (1.9 for $\mathrm{Cu}$ and 1.8 for Fe), but the equilibrium solubility is near zero at room temperature [33]. Interestingly, mechanical alloying can extend the solubility limit of $\mathrm{Fe}$ in $\mathrm{Cu}$ to more than equiatomic composition. As a result, the $\mathrm{Cu}$ lattice parameter increases [27], the displacement of the $\mathrm{Cu}$ peak positions to smaller angles occurs and the $\mathrm{Cu}(111)$ peak can present an overlapping with the Fe (110) peak, which is attributed to a magneto-volume effect, where Fe atoms promote repulsion between $\mathrm{Cu}$ atoms. Additionally, if the exposing time of the sample to X-ray radiation is not sufficient or the noise and background are high, the small peaks of the Fe may be indistinguishable [33]. Therefore, a completely fcc-Cu solid solution containing a supersaturated $\mathrm{Fe}$ is formed after mechanical alloying, resulting in the disappearance of (bcc) $\alpha$-Fe peaks.

Fig. 2 is the XRD pattern of the Cu95Fe 5 immiscible composite 

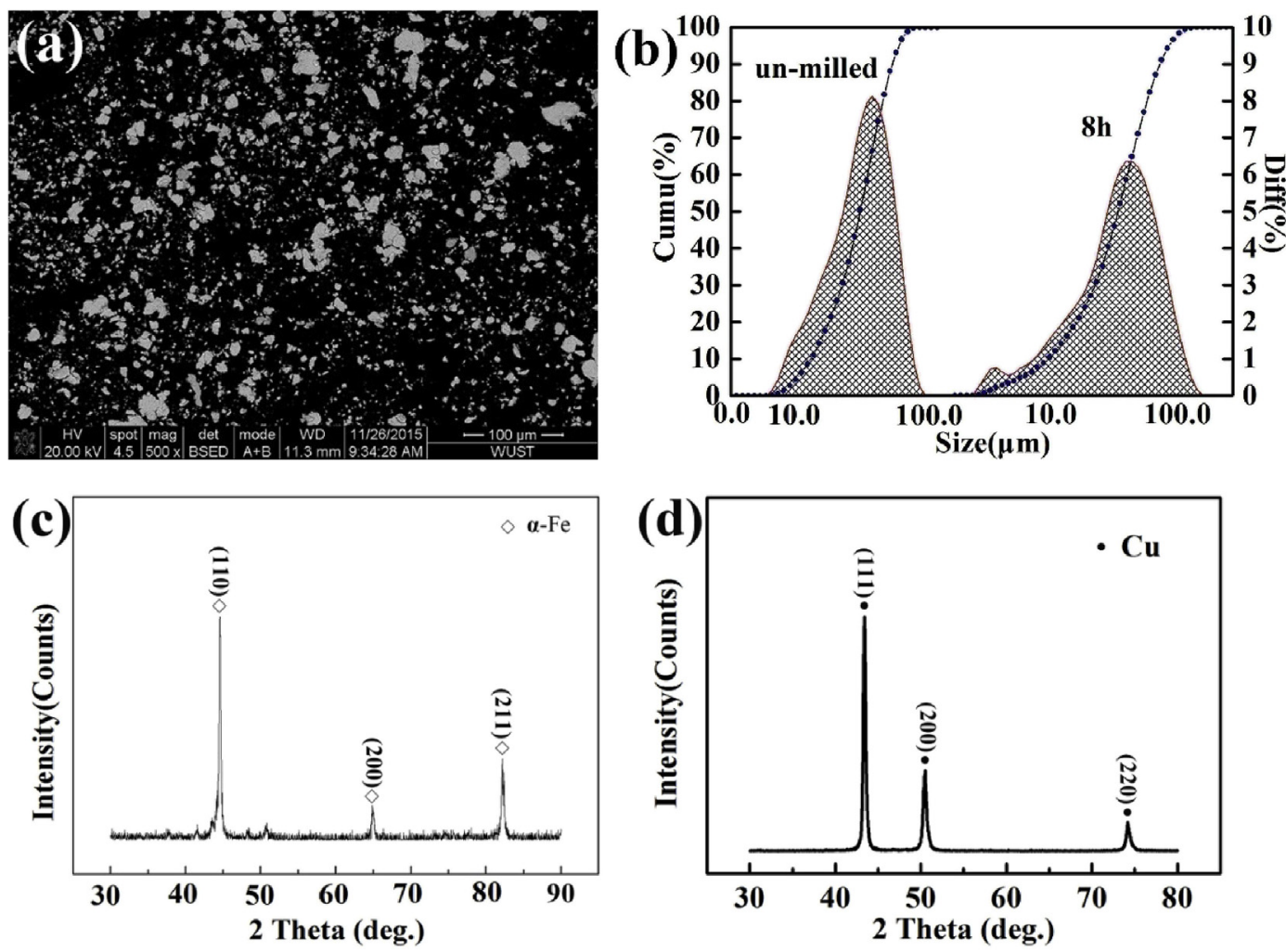

Fig. 1. (a) SEM image of composite powder, (b) size distribution of un-milled and milled composite powder, (c) XRD of Fe-based powder, (d) XRD of milled Cu-Fe composite powder.

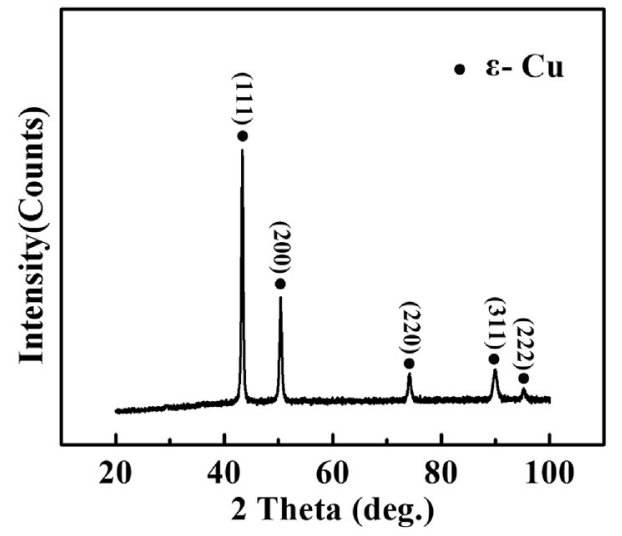

Fig. 2. XRD pattern of the Cu95Fe5 immiscible composite coating.

coating. It can be seen that the fcc $\varepsilon$-Cu phase is formed but bcc $\alpha$-Fe phase is not detected in the immiscible composite coating. Despite this fact of low Fe content, it could not be concluded that Fe has dissolved completely into fcc $\varepsilon$-Cu phase, which can be confirmed by the microstructure characteristics of the immiscible composite coating, as shown in Figs. 3 and 4.

Fig. 3 shows the microstructure of the Cu95Fe5 immiscible composite coating. It is apparent that the Cu95Fe5 immiscible composite coating does not appear the demixing phenomenon compared with the previous studies $[13,15]$, which reported that the microstructure of Cu65Fe35 immiscible composite coating presented the $\mathrm{Fe}_{\mathrm{p}} / \mathrm{Cu}-\mathrm{Cu}_{\mathrm{p}} / \mathrm{Fe}-\mathrm{Fe} / \mathrm{Cu}$ "sandwich-layer structure" and $\mathrm{Cu}_{\mathrm{p}} / \mathrm{Fe}-\mathrm{Fe}_{\mathrm{p}} / \mathrm{Cu}$ "duplex-layer structure" on the $\mathrm{Cu}$-substrate and Fe-substrate, respectively. Fig. 3a shows a typical crosssectional image of the immisble coating. Smooth and crack-free immiscible composite coating is formed and has a metallurgically bonding with the substrate. Fig. $3 \mathrm{~b}$ is the microstructure at the bottom of the immisble coating, indicating that large amounts of spherical Fe-rich particles are homogeneously distributed within the $\mathrm{Cu}$-rich matrix. Fig. $3 \mathrm{c}$ and $\mathrm{d}$ are the microstructure at the center and top of the immiscible composite coating, respectively. Obviously, the size variation of the spherical Fe-rich particles is remarkable and presents an increasing trend from the bottom to the top. As a result, the larger spherical Fe-rich particles are apt to be distributed at the top of the immiscible composite coating.

Fig. 4a shows a typical morphology of Fe-rich particles dispersed within the $\varepsilon$-Cu matrix. The EDS results (Fig. $4 \mathrm{~b}$ and c) indicate that the spherical particle is noticeably rich in Fe and contains a supersatured $\mathrm{Cu}$ (15.61 wt\%), whereas the matrix is rich in $\mathrm{Cu}$ and contains a supersaturated $\mathrm{Fe}$ (4.8 wt\%). Moreover, $\mathrm{Cr}$ and $\mathrm{Si}$ are slightly depleted in the spherical particle and matrix. According to the results of XRD (Fig. 2) and EDS analysis (Fig. 4b and c), it is reasonable to infer that the spherical Fe-rich particle and $\mathrm{Cu}$-rich matrix are $\alpha$-Fe and $\varepsilon$-Cu phases, respectively. Therefore, the Cu95Fe5 homogeneous immiscible composite coating is composed of bcc $\alpha$-Fe and fcc $\varepsilon$-Cu phases.

\subsection{Properties of immiscible composite coating}

Fig. 5 shows the microhardness of the Cu95Fe5 immiscible composite coating. It can be seen that the maximum microhardness is $176.8 \mathrm{HV}_{0.2}$ at the bottom of the immiscible composite coating. With increasing distance from the surface of substrate, the microhardness first decreases, and then keeps approximately content $\left(\sim 153 \mathrm{HV}_{0.2}\right)$, which is equal to the microhardness of the substrate $\left(153.3 \mathrm{HV}_{0.2}\right)$ and lower than that of the heat-affected-zone (HAZ) $\left(\sim 174.2 \mathrm{HV}_{0.2}\right)$. However, the microhardness of the immiscible composite coating is higher than that of Brass $\left(137.7 \mathrm{HV}_{0.2}\right)$, 


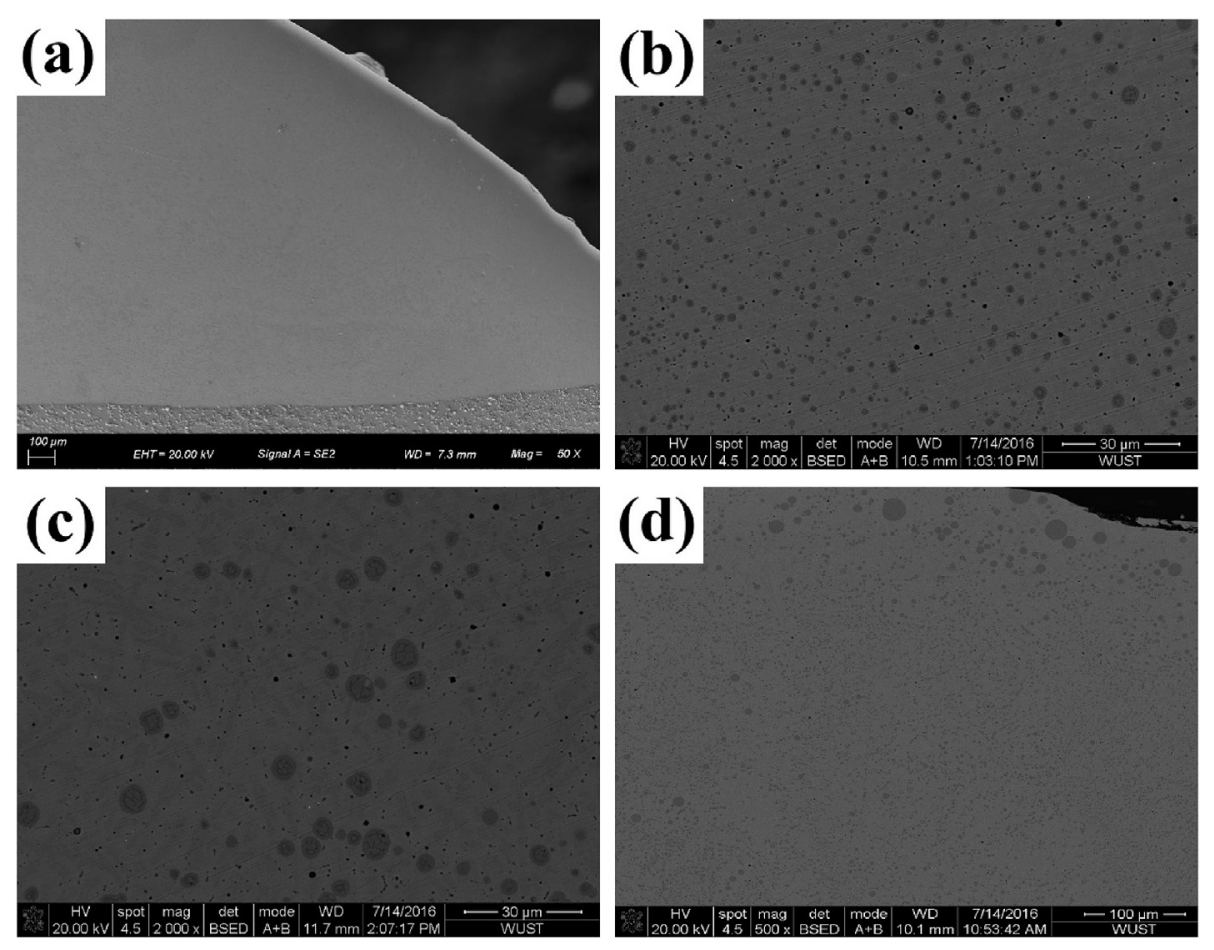

Fig. 3. Microstructure of the Cu95Fe5 immiscible composite coating: (a) cross-sectional morphology, (b) microstructure at the bottom, (c) microstructure at the center, (d) microstructure at the top.
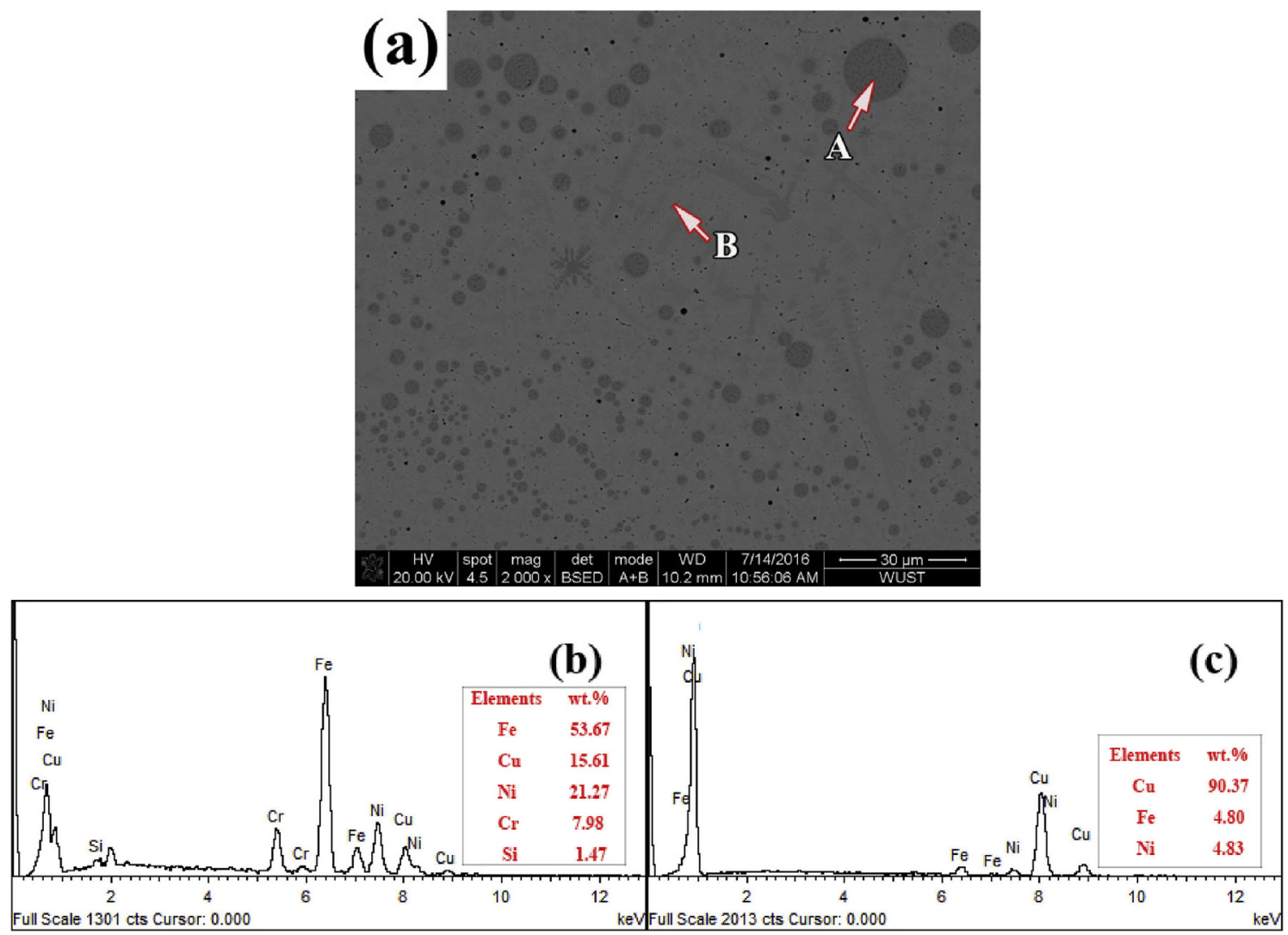

Fig. 4. (a) Morphology of spherical particles dispersed within the matrix in the Cu95Fe5 immiscible composite coating. EDS results of (b) particle (marked A) and (c) matrix (marked B). 


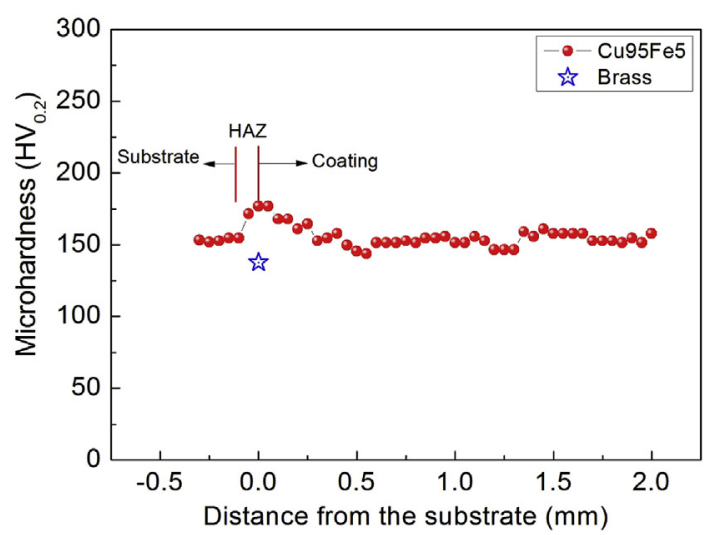

Fig. 5. Microhardness of the Cu95Fe5 immiscible composite coating.

indicating that the immiscible composite coating is strengthened due to large amounts of spherical Fe-rich particles dispersed within the $\mathrm{Cu}$-rich matrix.

Fig. 6a shows the polarization curves of the Cu95Fe5 immiscible composite coating and Brass in $3.5 \mathrm{wt} \% \mathrm{NaCl}$ solution at room temperature. According to the intersection of cathode and anode polarization curves, the corrosion potential $\left(\mathrm{E}_{\text {corr }}\right)$ and current density $\left(\mathrm{I}_{\text {corr }}\right)$ are calculated by Tafel extrapolation method from the respective curves and are summarized in Table 1. Generally, the corrosion potential $\mathrm{E}_{\text {corr }}$ reflects the corrosion thermodynamics of material. The larger the corrosion potential $\mathrm{E}_{\mathrm{corr}}$ is, the lower the corrosion trend of material is. The corrosion current density $\mathrm{I}_{\text {corr }}$ reflects the corrosion rate of material. The larger the current density $\mathrm{I}_{\text {corr }}$ is, the higher the corrosion rate is. The immiscible
Table 1

Corrosion potential ( $\left.\mathrm{E}_{\text {corr }}\right)$ and corrosion current density ( $\left.\mathrm{I}_{\text {corr }}\right)$ of the Cu95Fe5 homogeneous immiscible coating and brass obtained from potentiodynamic curves in Fig. 6a.

\begin{tabular}{lll}
\hline Samples & $\mathrm{E}_{\text {corr }}(\mathrm{mV})$ & $\mathrm{I}_{\text {corr }}\left(\mu \mathrm{A} \mathrm{cm}^{-2}\right)$ \\
\hline Brass & -585 & 2.622 \\
Immiscible composite coating & -536 & 1.405 \\
\hline
\end{tabular}

composite coating has a relatively higher $\mathrm{E}_{\mathrm{corr}}(-0.536 \mathrm{~V})$ and lower $\mathrm{I}_{\text {corr }}\left(1.405 \mathrm{~mA} \mathrm{~cm}^{-2}\right)$ than Brass $\left(-0.585 \mathrm{~V}\right.$ and $\left.2.622 \mathrm{~mA} \mathrm{~cm}^{-2}\right)$. It indicates that the immiscible composite coating has a relatively higher corrosion resistance than Brass, which can be further confirmed by the results of Nyquist and Bode curves (Fig. 6b and c). As shown in Fig. 6b, the electrode process of the immiscible composite coating is a hybrid control process of charge transfer and diffusion process [34], which can be confirmed by the result of electrochemical impedance spectroscopy (EIS) with semicircles in the high frequency range. It is apparent that the semicircle diameter of the immiscible composite coating is larger than that of Brass, indicating that the electrochemical corrosion resistance of the immiscible composite coating is higher than that of Brass. It can be seen from Fig. $6 c$ that the Bode plots of the immiscible composite coating and Brass consist of three distinctive segments that depend on the frequency range [34]. The immiscible composite coating possesses the phase angle of $56.5^{\circ}$ that is much higher than Brass with a phase angle of $56.3^{\circ}$ in a fixed $1 \mathrm{~Hz}$ frequency. The maximum phase angle between the immiscible composite coating and Brass is not significantly different. However, the modulus value of the immiscible composite coating is higher than that of Brass in the whole frequency range. It is worth noting that the modulus value of the immiscible composite coating is approximately seven times
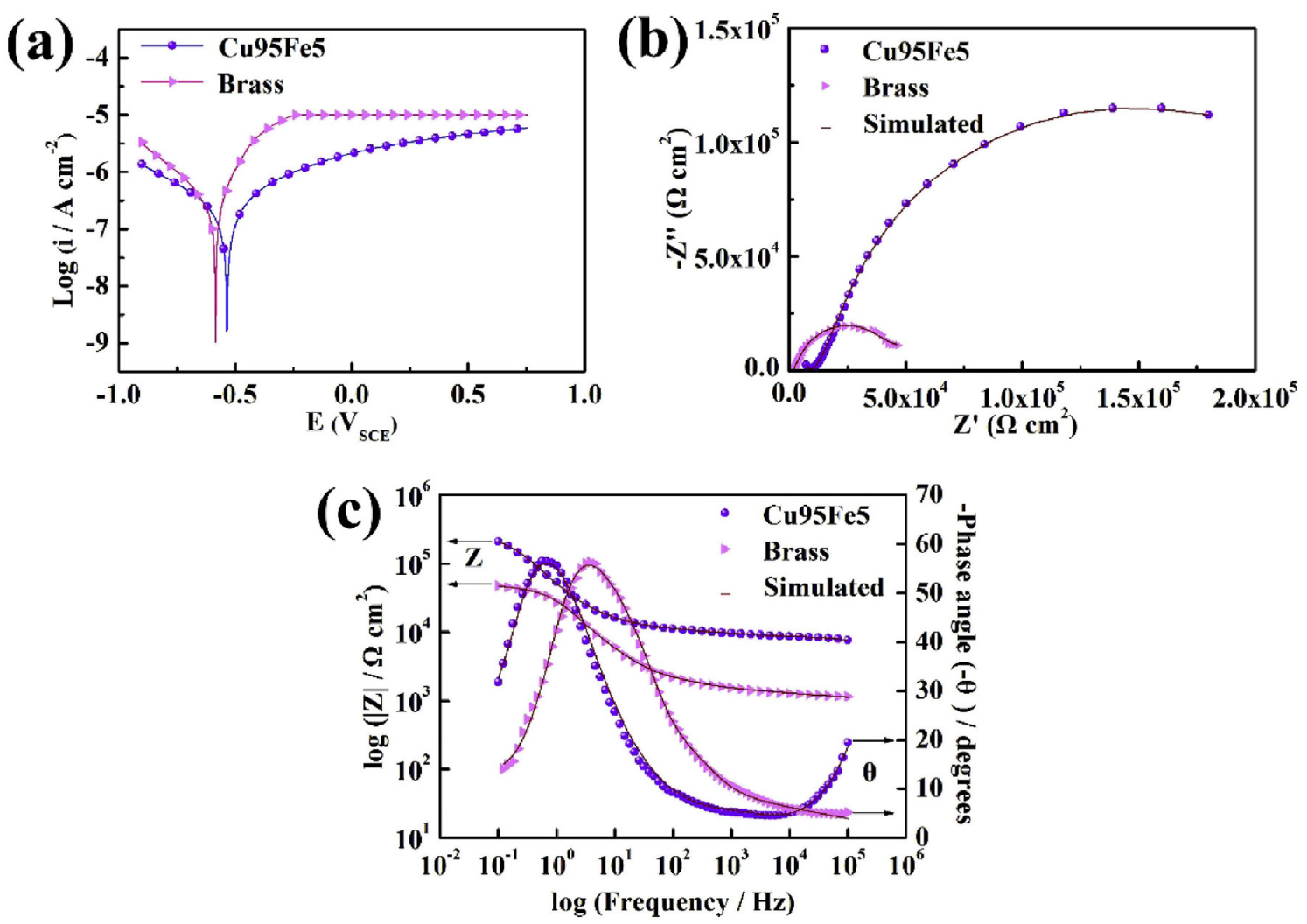

Fig. 6. (a) Polarization, (b) Nyquist, and (c) Bode curves of the Cu95Fe 5 immiscible composite coating and Brass in $3.5 \mathrm{wt} \% \mathrm{NaCl}$ solution. 
higher than that of Brass in the low impedance, indicating that the corrosion resistance of the immiscible composite coating is higher than that of Brass.

Fig. 7 shows the magnetic hysteresis loop of the immiscible composite coating at room temperature. The values of the saturated magnetization $\left(\mathrm{M}_{\mathrm{s}}\right)$ is $\sim 9.19 \mathrm{emu} / \mathrm{g}$. The corresponding coercivity is 9.25 Oe in terms of $\mathrm{H}_{\mathrm{C}}=\left|\mathrm{H}_{1}-\mathrm{H}_{2}\right| / 2$, where $\mathrm{H}_{1}$ and $\mathrm{H}_{2}$ are the left and right coercive fields, respectively. Wang et al. [35] produced the $\mathrm{CoCrCuFeNiTi}_{\mathrm{X}}$ high-entropy alloys by arc melting and found that their $\mathrm{M}_{\mathrm{s}}$ was lower than $2 \mathrm{emu} / \mathrm{g}$. Therefore, the immiscible composite coating presents soft ferromagnetic characteristics of low coercivity and high permeability, which can be expected to have a good application as the soft magnetic materials by further improving the distribution of Fe-rich particles in the $\mathrm{Cu}$-rich matrix and adjusting the alloying elements, such as $\mathrm{Fe}, \mathrm{Ni}, \mathrm{Si}, \mathrm{Cr}$ and $\mathrm{B}$. Moreover, the magnetic belt ring has a very small area, which is beneficial to reduce the magnetic loss of the immiscible composite coating under external magnetic field.

\section{Discussion}

Generally, laser cladding can obtain a rapid cooling at a rate up to $10^{6-7} \mathrm{~K} / \mathrm{s}$ [28]. Hence, the molten Cu-Fe alloy can easily obtain a considerable supercooling to enter the metastable liquid immiscible gap and subsequently can separate into two melts due to liquid phase separation (LPS): a Fe-rich melt $\left(\mathrm{L}_{1}\right)$ and a $\mathrm{Cu}$-rich melt $\left(\mathrm{L}_{2}\right)$, as shown in Fig. 10a and b. In order to minimize the surface energy, the $\mathrm{L}_{1}$ melt can shrink into many spherical liquid droplets, which are encapsulated by the $\mathrm{L}_{2}$ melt. As a result, large amounts of spherical Fe-rich particles as the minor phase are embedded within the $\mathrm{Cu}$-rich matrix as the major phase after rapid solidification, as shown in Fig. 3a $\sim$ d.

Furthermore, the size of Fe-rich particle presents an increasing tendency from the bottom to the top of the immiscible composite coating. This is due to the effects of Marangoni motion, which is caused by the temperature gradient and surface tension gradient between spherical liquid droplets and liquid matrix, and Stokes motion, which results from the gravity field. The liquid droplets can grow into larger liquid droplets at the expense of smaller liquid droplets due to coalescence caused from collisions of liquid droplets [36-38]. The motion is induced by the long-range, diffusion interaction among the Fe-rich liquid droplets with a difference in size, resulting in a concentration gradient from a smaller to a larger Fe-rich liquid droplets. As a result, the diffusion-induced coupling between two neighboring Fe-rich liquid droplets can result in an attractive interaction and a direct collision between them, which is

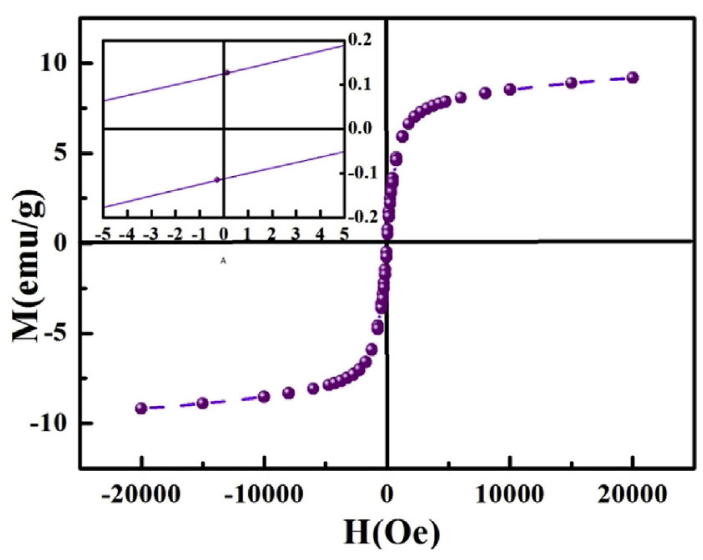

Fig. 7. Magnetic hysteresis loop of the Cu95Fe5 immiscible composite coating. called as a "diffusion-coupling mechanism" or a "gradient-inducedcoupling mechanism" $[39,40]$. Therefore, a larger Fe-rich liquid droplet acts a sink, while a smaller one acts as a source. A larger Ferich liquid droplet is grown with the disappearance of small Fe-rich liquid droplets. The velocities of Marangoni motion, $\mathrm{V}_{\mathrm{M}}$, and Stokes motion, $V_{S}$, can be determined by the following equations, respectively [22]:

$V_{M}=\frac{-2 r}{3\left(3 \mu_{1}+2 \mu_{2}\right)} \cdot \frac{\partial \sigma}{\partial T} \cdot \frac{\partial T}{\partial z}$

$V_{S}=\frac{2 g \Delta \rho r^{2}\left(\mu_{1}+\mu_{2}\right)}{3 \mu_{2}\left(3 \mu_{1}+2 \mu_{2}\right)}$

where $r$ is the radius of Fe-rich liquid droplet, $\mu_{1}$ and $\mu_{2}$ are the viscosities of Fe-rich liquid droplet and $\mathrm{Cu}$-rich matrix liquid, respectively, $\partial \sigma / \partial \mathrm{T}$ is the gradient of the interfacial energy between Fe-rich liquid droplet and $\mathrm{Cu}$-rich matrix liquid as a function of temperature, $\frac{\partial T}{\partial z}$ is the temperature gradient, $\mathrm{g}$ is the gravity coefficient $\left(\mathrm{g}=9.8 \mathrm{~m} / \mathrm{s}^{2}\right), \triangle \rho$ is the difference of density between Ferich liquid droplet and $\mathrm{Cu}$-rich matrix liquid. The temperature of the molten pool during laser cladding can be calculated as follows [41]:

$$
\begin{aligned}
\mathrm{T}(x, y, z)= & T_{0}+\frac{\alpha P}{\pi^{3} k r} \int_{0}^{\infty} \frac{1}{1+S^{2}} \exp \left\{-\frac{s^{2}}{1+s^{2}} \times\left[\left(\frac{x}{r}-\frac{a r}{2 s^{2}}\right)^{2}\right.\right. \\
& \left.\left.+\left(\frac{y}{r}\right)^{2}\right]-s^{2}\left(\frac{z}{r}\right)^{2}\right\} d s
\end{aligned}
$$

where $\mathrm{T}_{0}$ is the preheated temperature of substrate, $\mathrm{P}$ is the laser power, $\alpha$ is the absorption coefficient of the substrate, $r$ is the radius of laser spot, $a=\rho \mathrm{cV} / \mathrm{k}, \mathrm{k}$ is the thermal conductivity coefficient, $\rho$ is the density, $\mathrm{c}$ is the thermal capacity and $\mathrm{V}$ is the laser scanning speed. During laser cladding, the movement velocity of Fe-rich liquid droplets, $\Delta \mathrm{V}$, is determined by $V_{M}$ and $V_{S}$, and can be described as follows [14]:

$\Delta \mathrm{V}=V_{M}+V_{S}$

The cooling rate as high as $10^{6-7} \mathrm{~K} / \mathrm{s}$ may be achieved during laser cladding so that the solidification time of Fe-rich droplets after the LPS is greatly shortened, which can lead to enhanced microstructure refinement because the growth or coarsening time of $\mathrm{Fe}$ rich liquid droplets are inhibited [30]. According to parameters listed in Table 2, the temperature and temperature gradient of the molten pool during laser cladding are shown in Fig. 8. Correspondingly, the calculated velocities of Marangoni motion and Stokes motion at $1650 \mathrm{~K}$ (Fig. 9) demonstrate that the $V_{M}$ of Fe-rich liquid droplet has a linear relationship with its droplet size $r$, whereas the $V_{S}$ has a square relationship with its droplet size $r$. The velocity of Fe-rich liquid droplet will be zero when $r$ increases to a certain critical radius $r_{0}$. If $r<r_{0}$, the velocity of Fe-rich liquid droplet, $\Delta \mathrm{V}$, is larger than zero, indicating that Marangoni motion is the dominant mechanism for movement of Fe-rich liquid droplets and the movement direction is toward the top of the molten pool. As a result, small Fe-rich liquid droplets collide with each other, coagulate and then grow into larger liquid droplets in the course of the upward migration, as shown in Fig. 10c. If $r=r_{0}$, the velocity of Fe-rich liquid droplet, $\Delta \mathrm{V}$, is equal to zero, suggesting that the Ferich liquid droplets will remain stationary state and the size of Fe-rich liquid droplets is uniform, as shown in Fig. 10d. If $r>r_{0}$, the velocity of Fe-rich liquid droplet, $\Delta \mathrm{V}$, is less than zero, implying that 

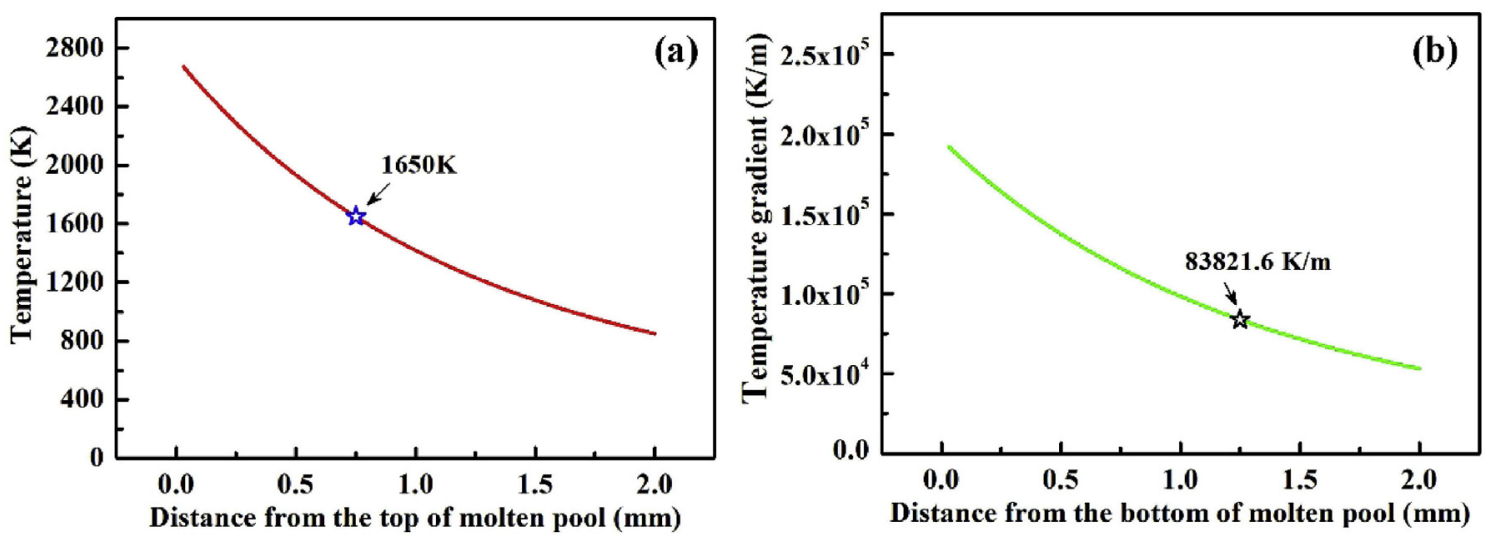

Fig. 8. (a) Temperature distribution, (b) temperature gradient of the molten pool during laser cladding.

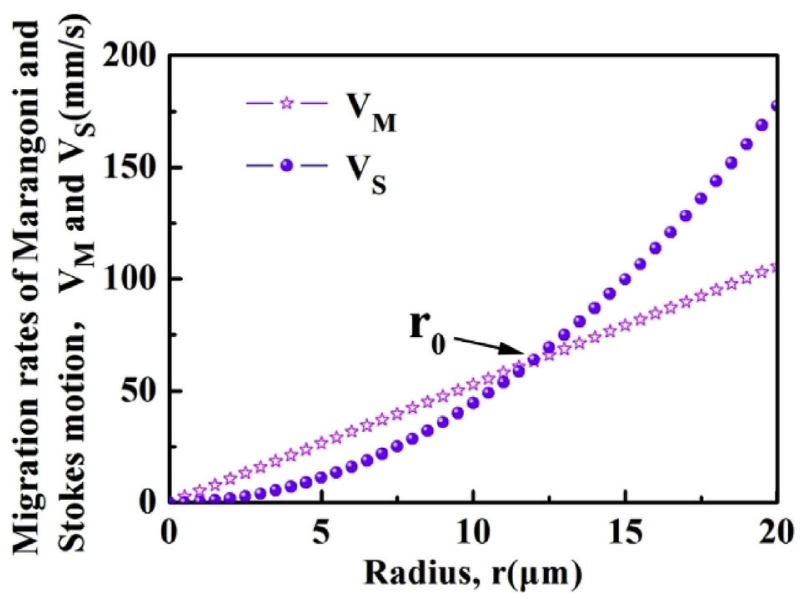

Fig. 9. Calculated velocities of Marangoni migration and Stokes motion versus Fe-rich droplet radius. the movement of Fe-rich liquid droplets is dependent on Stokes motion and can move toward the bottom of the molten pool. As a result, the Fe-rich liquid droplets can grow due to coalescence of moving liquid droplets, as shown in Fig. 10e.

For the immiscible composite coating, the calculated critical radius, $r_{0}$, is $\sim 2.3 \mu \mathrm{m}$, which is much larger than the measured radius, $\mathrm{r}(\sim 1.5 \mu \mathrm{m})$. It is apparent that the Fe-rich liquid droplets move towards the top of the molten pool driven by the dominant mechanism of Marangoni motion, leading to the coalescence and collisions of the moving Fe-rich liquid droplets. Furthermore, as an increase in size of the Fe-rich liquid droplet, its $V_{M}$ also increases, which is more favorable to move towards the top of the molten pool. Additionally, compared to the Cu65Fe35 immiscible composite coating, the iron content is only $5 \mathrm{wt} \%$ in the cladding powder and some iron atoms can dissolve into $\mathrm{Cu}$ to form the $\mathrm{Cu}-$ rich matrix containing a supersatured Fe (Fig. 4). As a result, these moving Fe-rich liquid particles can be "frozen" within the $\mathrm{Cu}$-rich matrix during laser cladding, due to lack of enough time to grow
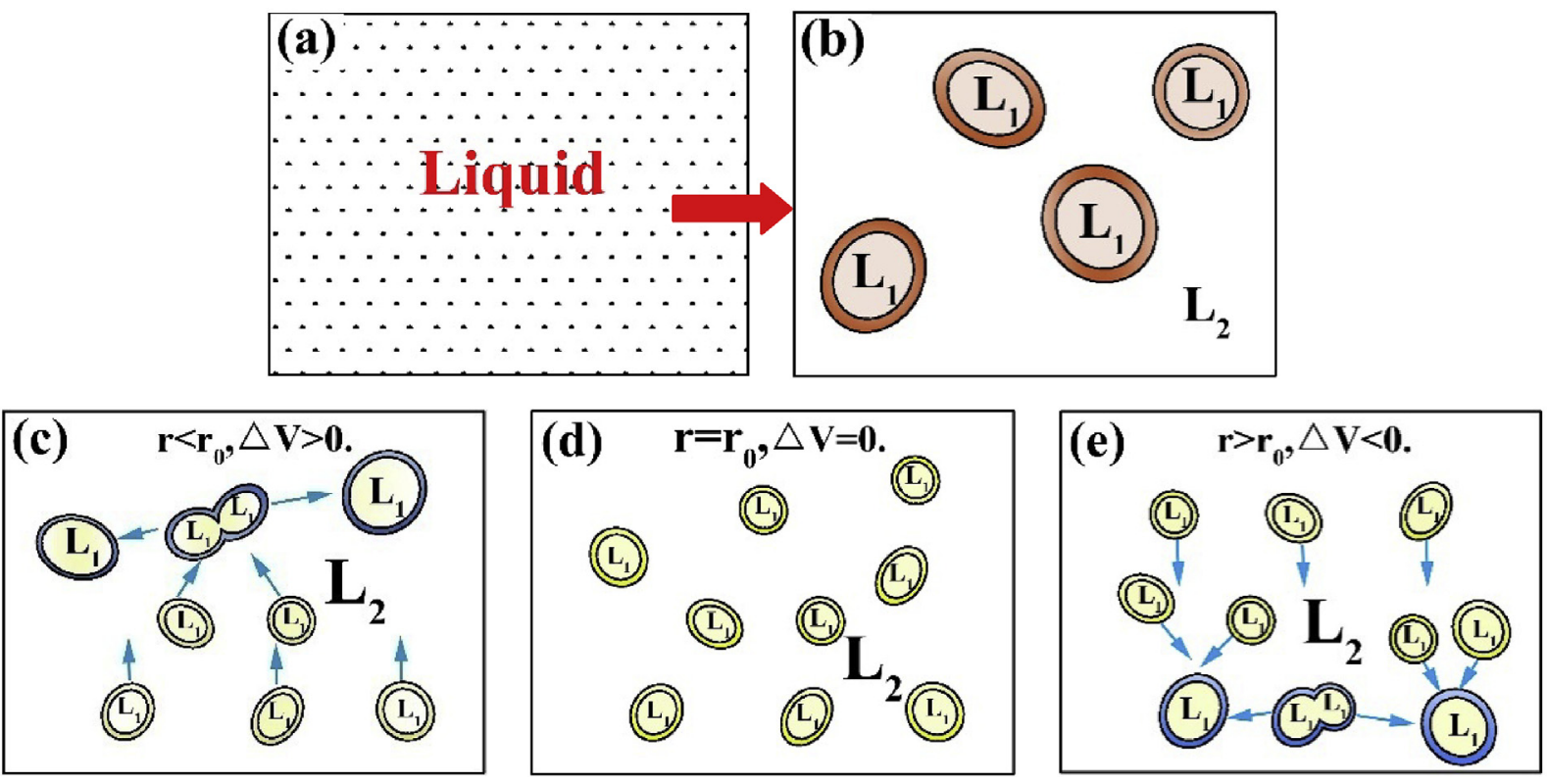

Fig. 10. Schematic illustration of morphology evolution of Fe-rich liquid droplets drived by Marangoni migration in the Cu-rich melt. 
Table 2

Parameters used to calculate the velocities of Stokes and Marangoni motion.

\begin{tabular}{|c|c|c|c|}
\hline Parameters & Value & Unit & Reference \\
\hline Viscosity of Fe droplet, $\mu_{1}$ & $5.443 \times 10^{-3}$ & $\mathrm{~N} \mathrm{~s} / \mathrm{m}^{2}$ & [37] \\
\hline Viscosity of $\mathrm{Cu}$ liquid, $\mu_{2}$ & $4 \times 10^{-3}$ & $\mathrm{~N} \mathrm{~s} / \mathrm{m}^{2}$ & [37] \\
\hline Density of Fe liquid, $\rho_{1}$ & $7.0 \times 10^{3}$ & $\mathrm{~kg} \mathrm{~m}^{-3}$ & [37] \\
\hline Density of $\mathrm{Cu}$ liquid, $\rho_{2}$ & $7.9 \times 10^{3}$ & $\mathrm{~kg} \mathrm{~m}^{-3}$ & [37] \\
\hline$\partial \sigma / \partial \mathrm{T}$ & $-0.5 \times 10^{-6}$ & $\mathrm{~J} \mathrm{~m}^{-2} \mathrm{~K}^{-1}$ & [37] \\
\hline Gravitational acceleration, $\mathrm{g}$ & 9.8 & $\mathrm{~m} \mathrm{~s}^{-2}$ & [29] \\
\hline Preheated temperature, $T_{0}$ & 298 & $\mathrm{~K}$ & [30] \\
\hline Absorption coefficient of the substrate, $\alpha$ & 0.3 & & {$[30]$} \\
\hline Thermal conductivity coefficient, $\mathrm{k}$ & 36 & $\mathrm{~W} \mathrm{~m} \mathrm{~m}^{-1} \mathrm{~K}^{-1}$ & [30] \\
\hline Density of the substrate, $\rho$ & $7.84 \times 10^{3}$ & $\mathrm{~kg} \mathrm{~m}^{-3}$ & [30] \\
\hline Thermal capacity, c & 502 & $\mathrm{~J} \mathrm{~kg}^{-1} \mathrm{~K}^{-1}$ & {$[30]$} \\
\hline Laser power, $\mathrm{P}$ & 3.0 & $\mathrm{~kW}$ & \\
\hline The radius of laser spot, $r$ & 4 & $\mathrm{~mm}$ & \\
\hline
\end{tabular}

up. This can inhibit the occurrence of severe segregation, and therefore avoid the appearance of demixing and delamination in the Cu95Fe 5 immiscible composite coating, which is characterized by large amounts of Fe-rich particles dispersed within the whole Cu-rich matrix (Fig. 3), compared to the Cu65Fe35 immiscible composite coating with $\mathrm{Fe}_{\mathrm{p}} / \mathrm{Cu}-\mathrm{Cu}_{\mathrm{p}} / \mathrm{Fe}-\mathrm{Fe}_{\mathrm{p}} / \mathrm{Cu}$ "sandwich-layer structure" and $\mathrm{Cu}_{\mathrm{p}} / \mathrm{Fe}-\mathrm{Fe}_{\mathrm{p}} / \mathrm{Cu}$ "duplex-layer structure" $[13,15]$.

The related properties of the Cu95Fe5 immiscible composite coating have been improved markedly as a result of improvement in homogeneous distribution of the Fe-rich particles within the $\mathrm{Cu}$ rich matrix. For example, the microhardness of the Cu95Fe5 immiscible composite coating present not a sharp gradient distribution [13], but a homogeneous distribution, and is higher than that of Brass. This is because the supersatured Fe (4.8 wt\%) dissolved into the $\mathrm{Cu}$-rich matrix can play an important role in solidsolution strengthening. Additionally, large amounts of spherical Ferich particles are dispersed homogeneously within the $\mathrm{Cu}$-rich matrix, resulting in the dispersion strengthening. The maximum microhardness is located at the bottom of the Cu95Fe 5 immiscible composite coating. This is because some iron atoms from Fesubstrate can diffuse into the bottom of the immiscible composite coating, whose microhardness can be further strengthened. Moreover, the corrosion resistance of the immiscible composite coating is relatively higher than Brass, which is determined by the microstructure of the immiscible composite coating. Due to a potential difference between the spherical Fe-rich particles and the $\mathrm{Cu}$-rich matrix, the chemical microcell is susceptible to form between them [42]. Especially, the Cu-rich matrix with high potential is the cathode, and the Fe-rich particles with low potential is the anode, resulting in the formation of large cathode and small anode $[29,43]$. As a result, the Fe-rich particles can be corroded preferentially to protect the $\mathrm{Cu}$-rich matrix from being corroded. There are some bubbles popping up during the electrochemical corrosion testing, confirming that the hydrogen evolution corrosion occurs in the cathodic, leading to corrosion mitigation of Cu-rich matrix in the cathodic. Moreover, the stable corrosion products cannot be formed, though $\mathrm{Fe}$ can interact with $\mathrm{NaCl}$ solution. Correspondingly, the reaction equation can be described as follows [15]:

$2 \mathrm{H}_{2} \mathrm{O}+2 e^{-} \rightarrow 2 \mathrm{OH}^{-}+\mathrm{H}_{2} \uparrow$

$\mathrm{Fe}+2 \mathrm{Cl}^{-} \rightarrow \mathrm{FeCl}_{2}+2 e^{-}$

$4 \mathrm{FeCl}_{2}+8 \mathrm{OH}^{-}+\mathrm{O}_{2} \rightarrow 2 \mathrm{Fe}_{2} \mathrm{O}_{3} \cdot 2 \mathrm{H}_{2} \mathrm{O}+8 \mathrm{Cl}^{-}+2 \mathrm{H}_{2}$

Therefore, the cathodic protection of the $\mathrm{Cu}$-rich matrix can be achieved, leading to an improvement in corrosion resistance of the Cu95Fe5 immiscible coating compared to that of Brass.

\section{Conclusions}

(1) The milled Cu95Fe5 composite powder presents a polygonal morphology and is mainly composed of a completely fcc-Cu solid solution. The immiscible composite coating without segregation structure, which is characterized by many spherical $\alpha$-Fe particles embedded homogeneously within the $\varepsilon$-Cu matrix, is successfully prepared by the combination of mechanical alloying and laser cladding.

(2) The $\alpha$-Fe particles are in radius of $\sim 1.5 \mu \mathrm{m}$ which is much smaller than the calculated critical radius $(\sim 2.3 \mu \mathrm{m})$, suggesting that the Fe-rich droplets are driven by the dominant mechanism of Marangoni motion. Under the action of Marangoni migration, small Fe-rich liquid droplets can grow into larger liquid droplets due to coalescence and collisions, resulting in the microstructure characteristic of spherical Ferich particles embedded within the $\mathrm{Cu}$-rich matrix, without the appearance of demixing and delamination.

(3) The immiscible composite coating presents a saturated magnetization $\left(\mathrm{M}_{\mathrm{S}}\right)$ of $\sim 9.19 \mathrm{emu} / \mathrm{g}$ and a low coercivity $\left(\mathrm{H}_{\mathrm{c}}\right)$ of $\sim 9.25$ Oe, respectively. Moreover, the microhardness of the immiscible composite coating $\left(\sim 153 \mathrm{HV}_{0.2}\right)$ is higher than that of Brass $\left(137.7 \mathrm{HV}_{0.2}\right)$, and the immiscible composite coating has a relatively higher $\mathrm{E}_{\text {corr }}(-0.536 \mathrm{~V})$ and lower $\mathrm{I}_{\text {corr }}$ $\left(1.405 \mathrm{~mA} \mathrm{~cm}^{-2}\right)$ than Brass $\left(-0.585 \mathrm{~V}\right.$ and $\left.2.622 \mathrm{~mA} \mathrm{~cm}^{-2}\right)$. Obviously, the microhardness and corrosion resistance of the immiscible composite coating are improved significantly compared to those of Brass.

\section{Acknowledgements}

This work was financially supported by the National Natural Science Foundation of China (Grant No. 51471084) and the Outstanding Youth Foundation of Jiangxi Province (20162BCB23039).

\section{References}

[1] Y. Nakagawa, Liquid immiscibility in copper-iron and copper-cobalt systems in the supercooled state, Acta Metall. 6 (1958) 704-711.

[2] R.P. Shi, C.P. Wang, D. Wheeler, X.J. Liu, Y. Wang, Formation mechanisms of self-organized core/shell and core/shell/corona microstructures in liquid droplets of immiscible alloys, Acta Mater. 61 (2013) 1229-1243.

[3] B. Ma, J. Li, Z. Peng, G. Zhang, Structural morphologies of Cu-Sn-Bi immiscible alloys with varied compositions, J. Alloy. Comp. 535 (2012) 95-101.

[4] A. Munitz, A.M. Bamberger, S. Wannaparhun, R. Abbaschian, Effect f supercooling and cooling rate on the microstructure of $\mathrm{Cu}-\mathrm{Co}-\mathrm{Fe}$ alloys, J. Mater. Sci. 41 (2006) 2749-2759.

[5] B. Ma, J. Li, Z. Xu, Z. Peng, Fe-shell/Cu-core encapsulated metallic phase change materials prepared by aerodynamic levitation method, Appl. Energy 132 (2014) 568-574.

[6] A. Munitz, R. Abbaschian, Liquid separation in $\mathrm{Cu}-\mathrm{Co}$ and $\mathrm{Cu}-\mathrm{Co}-\mathrm{Fe}$ alloys 
solidified at high cooling rates, J. Mater. Sci. 33 (1998) 3639-3649.

[7] K. Zhang, X. Bian, Y. Li, C. Yang, H. Yang, Y. Zhang, High-efficiency control of phase separation in Al-based immiscible alloys, J. Alloy. Comp. 639 (2015) $563-570$.

[8] V. Elofsson, G.A. Almyras, B. Lü, R.D. Boyd, K. Sarakinos, Atomic arrangement in immiscible Ag-Cu alloys synthesized far-from-equilibrium, Acta Mater. 110 (2016) 114-121.

[9] Y.H. Wu, W.L. Wang, Z.C. Xia, B. Wei, Phase separation and microstructure evolution of ternary Fe-Sn-Ge immiscible alloy under microgravity condition, Comput. Mater. Sci. 103 (2015) 179-188.

[10] T. Nagase, M. Takemura, M. Matsumuro, M. Matsumoto, Y. Fujii, Design and microstructure analysis of globules in $\mathrm{Al}-\mathrm{Co}-\mathrm{La}-\mathrm{Pb}$ immiscible alloys with an amorphous phase, Mater. Des. 117 (2017) 338-345.

[11] F. Dai, C. Cao, B. Wei, Phase separation and rapid solidification of liquid Cu60Fe30Co10 ternary peritectic alloy, Sci. China Phys. Mech. Astron. 50 (2007) 509-518.

[12] S. Zhou, C. Wu, T. Zhang, Z. Zhang, Carbon nanotube-and Fe $\mathrm{Fe}_{\mathrm{p}}$-reinforced copper-matrix composites by laser induction hybrid rapid cladding, Scripta Mater. 76 (2014) 25-28.

[13] S. Zhou, J. Lei, Z. Xiong, X. Dai, J. Guo, Z. Gu, Synthesis of $\mathrm{Fe}_{\mathrm{p}} / \mathrm{Cu}_{\mathrm{Cu}} / \mathrm{Fe}$ duplex composite coatings by laser cladding, Mater. Des. 97 (2016) 431-436.

[14] S. Zhou, T. Zhang, Z. Xiong, X. Dai, C. Wu, Z. Shao, Investigation of $\mathrm{Cu}-\mathrm{Fe}-$ based coating produced on copper alloy substrate by laser induction hybrid rapid cladding, Optic Laser. Technol. 59 (2014) 131-136.

[15] X. Dai, S. Zhou, M. Wang, J. Lei, M. Xie, H. Chen, Effect of substrate types on the microstructure and properties of Cu65Fe 35 composite coatings by laser induction hybrid cladding. J. Alloy. Comp. 722 (2017) 173-182.

[16] F. Abdeljawad, P. Lu, N. Argibay, B.G. Clark, B.L. Boyce, S.M. Foiles, Grain boundary segregation in immiscible nanocrystalline alloys, Acta Mater. 126 (2017) 528-539.

[17] L. Fu, J. Yang, Q. Bi, W. Liu, Combustion synthesis immiscible nanostructured Fe-Cu alloy, J. Alloy. Comp. 482 (2009) L22-L24.

[18] X. Huang, T. Mashimo, Metastable bcc and fcc alloy bulk bodies in Fe-Cu system prepared by mechanical alloying and shock compression, J. Alloy. Comp. 288 (1999) 299-305.

[19] A. Bachmaier, M. Kerber, D. Setman, R. Pippan, The formation of supersaturated solid solutions in Fe-Cu alloys deformed by high-pressure torsion, Acta Mater. 60 (2012) 860-871.

[20] A. Kobayashi, K. Nagayama, Microstructure and solidification process of Fe-Cu immiscible alloy by using containless process, J. Jpn. Inst. Met. 81 (2017) $251-256$.

[21] Z.C. Xia, W.L. Wang, Y.H. Wu, S.B. Luo, B. Wei, Solidification pathways of ternary $\mathrm{Cu}_{62.5} \mathrm{Fe}_{27.5} \mathrm{Sn}_{10}$ alloy modulated through liquid undercooling and containless processing, Appl. Phys. A 122 (2016) 985.

[22] C.P. Wang, X.J. Liu, I. Ohnuma, R. Kainuma, K. Ishida, Formation of immiscible alloy powders with egg-type microstructure, Science 297 (2002) 990-993.

[23] L.C. Zhang, K.B. Kim, P. Yu, W.Y. Zhang, U. Kunz, J. Eckert, Amorphization in mechanically alloyed ( $\mathrm{Ti}, \mathrm{Zr}, \mathrm{Nb})-(\mathrm{Cu}, \mathrm{Ni})-\mathrm{Al}$ equiatomic alloys, J. Alloy. Comp. 428 (2007) 157-163.

[24] L.C. Zhang, J. Xu, Mechanically alloyed amorphous Ti50(Cu0.45Ni0.55)44xAlxSi4B2 alloys with supercooled liquid region, J. Mater. Res. 17 (2002) 1743-1749.
[25] L.C. Zhang, Z.Q. Shen, J. Xu, Mechanically milling-induced amorphization in Sn-containing Ti-based multicomponent alloy systems, Mater. Sci. Eng. A 394 (2005) 204-209.

[26] H.B. Lu, C.K. Poh, L.C. Zhang, Z.P. Guo, X.B. Yu, H.K. Liu, Dehydrogenation characteristics of Ti- and Ni/Ti-catalyzed Mg hydrides, J. Alloy. Comp. 481 (2009) 152-155.

[27] D.V. Maheswar Repaka, Vinay Sharma, R.V. Ramanujan, Near room temperature magnetocaloric properties and critical behavior of binary $\mathrm{Fe}_{\mathrm{x}} \mathrm{Cu}_{100-\mathrm{x}}$ nanoparticles, J. Alloy. Comp. 600 (2017) 575-582.

[28] A. Munitz, A. Venkert, P. Landau, M.J. Kaufman, R. Abbaschian, Microstructure and phase selection in supercooled copper alloys exhibiting metastable liquid miscibility gaps, J. Mater. Sci. 47 (2012) 7955-7970.

[29] S. Zhou, X. Dai, Z. Xiong, C. Wu, T. Zhang, Z. Zhang, Influence of Al addition on microstructure and properties of $\mathrm{Cu}-\mathrm{Fe}$-based coatings by laser induction hybrid rapid cladding, J. Mater. Res. 29 (2014) 865-873.

[30] X. Dai, S. Zhou, M. Wang, J. Lei, C. Wang, T. Wang, Microstructure evolution of phase separation $\mathrm{Fe}-\mathrm{Cu}-\mathrm{Cr}-\mathrm{C}$ composite coatings by laser induction hybrid cladding, Surf. Coating. Technol. 324 (2017) 518-525.

[31] J.T. Zhang, X.C. Cui, Y.T. Yang, Y.H. Wang, Solidification of the Cu-35 wt pct Fe alloys with liquid separation, Metall. Mater. Trans. A 44 (2013) 5544-5548.

[32] J. Trapp, B. Kieback, Solid-state reactions during high-energy milling of mixed powder, Acta Mater. 61 (2013) 310-320.

[33] M. Mojtahedi, M. Goodarzi, M.R. Aboutalebi, M. Ghaffari, V. Soleimanian, Investigation on the formation of $\mathrm{Cu}-\mathrm{Fe}$ nano crystalline super-saturated solid solution developed by mechanical alloying, J. Alloy. Comp. 550 (2013) 380-388.

[34] F. Mansfeld, Electrochemical impedance spectroscopy (EIS) as a new tool for investigating methods of corrosion protection, Electrochim. Acta 35 (1990) 1533-1544.

[35] X.F. Wang, Y. Zhang, Y. Qiao, G.L. Chen, Novel microstructure and properties of multicomponent CoCrCuFeNiTix alloys, Intermetallics 15 (2007) 357-362.

[36] J. He, J.Z. Zhao, L. Ratke, Solidification microstructure and dynamics of metastable phase transformation in undercooled liquid $\mathrm{Cu}-\mathrm{Fe}$ alloys, Acta Mater. 54 (2006) 1749-1757.

[37] N. Liu, F. Liu, W. Yang, Z. Chen, G.C. Yang, Movement of minor phase in undercooled immiscible $\mathrm{Fe}-\mathrm{Co}-\mathrm{Cu}$ alloys, J. Alloy. Comp. 551 (2013) $323-326$.

[38] I. Kaban, M. Köhler, L. Ratke, R. Nowak, N. Sobczak, N. Mattern, Phase separation in monotectic alloys as a route for liquid state fabrication of composite materials, J. Mater. Sci. 47 (2012) 8360-8366.

[39] H. Tanaka, A new coarsening mechanism of droplet spinodal decomposition, J. Chem. Phys. 103 (1995) 2361-2364.

[40] H. Tanaka, Coarsening mechanisms of droplet spinodal decomposition in binary fluid mixtures, J. Chem. Phys. 105 (1996) 10099-10114.

[41] D. Zeng, C. Xie, M. Wang, In situ synthesis and characterization of $\mathrm{Fe}_{\mathrm{p}} / \mathrm{Cu}$ composite coating on SAE 1045 carbon steel by laser cladding, Mater. Sci. Eng. A 344 (2003) 357-364.

[42] J. Lei, C. Shi, S. Zhou, Z. Gu, L.C. Zhang, Enhanced corrosion and wear resistance properties of carbon fiber reinforced Ni-based composite coating by laser cladding, Surf. Coating. Technol. 334 (2018) 274-285

[43] Y.S. Choi, D.H. Shin, J.G. Kim, Sacrificial anode cathodic protection of aluminum-coated steel for automotive muffles, Corrosion 63 (2007) 522-528. 